\title{
Effect of Regular Practice of Pranayama on Muscle Performance Capability among Garment Workers
}

\author{
Varsha SV \\ Assistant Professor, Department of Physiology, Sri Siddhartha Institute of Medical Science and Research Centre, Karnataka, India
}

Keywords: Garment workers, Handgrip strength, Muscle performance capability, Pranayama

\section{Corresponding author}

Varsha SV

Assistant Professor, Department of Physiology, Sri Siddhartha Institute of Medical Science and Research Centre, Karnataka, India

E-mail: drvarshasv@gmail.com

\begin{abstract}
Garment industry employs most of unskilled labour, it demands physical $\checkmark$ performance of the employees. There is a need to find tools which can enhance the muscle performance and overall health of the employees. Hence, the present study was undertaken to study the effect of regular practice of pranayama on muscle performance. Muscle performance was measured as hand grip strength in terms of Maximum Voluntary Contraction (MVC) and Time to Fatigue at 30\% of MVC on day 0 and day 30 of pranayama intervention. After analysing the data statistically, it was found that MVC was significantly $(\mathrm{p}<0.02)$ better in Post-Pranayama recording $(159.42 \pm 18.25)$ compared to Pre-Pranayama recording $(153.7 \pm 20.26)$. Time to fatigue at $30 \%$ MVC too was significantly higher during Post-Pranayama session $(210.22 \pm 18.651)$ than Pre-Pranayama session (189.58 \pm 25.05$)$. Effectiveness of pranayama on muscle performance was evidenced in this study.
\end{abstract}

India is the second largest manufacturer of textiles in the world (NITI). According to the data available, approximately $60 \%$ of the population employed in the garment industry are women. With garment industry employing most of unskilled labour, it demands physical performance of the employees.

Pranayama - a yogic practice of breath control is easy to perform and simple to practice as a part of daily routine. Regular practice of pranayama is said to improve parasympathetic tone and availability of energy and thus better physical/muscle performance capability (Mohinder and Malik, 1988).

In spite of knowing the benefits, there are very few studies done in the past to explore the effects of pranayama on physical performance. And also, considering the quantum of contribution by female workforce in the textile industry in turn global economy, there is a need for methods to improve their performance. Hence the present study was undertaken to assess the effect of regular practice of pranayama on physical performance among female garment workers. Since hand grip endurance is used as an indicator for muscle function, Muscle performance capability was measured in terms of handgrip strength (strength of upper limb muscles) and time for fatigue during sustained sub maximal isometric handgrip strength exercise.

\section{MATERIALS AND METHODS}

\section{Sample}

Sixty (60) female garment workers in the age group of 20 40 years from 3 different ready-made garment industries of Bengaluru were recruited for the study. History of anaemia, irregular menstrual cycle, present history of fever, history of asthma, tuberculosis, neurological abnormalities, Musculoskeletal disorders, and history of systemic diseases like 
diabetes mellitus and hypertension were excluded from the study. It was further confirmed that the subjects were not on hormonal therapy or oral contraceptives.

\section{Procedure}

Detailed explanation of the study was given to the subjects and informed consent was taken. The training session and assessment was done at respective garment factories. General physical examination was done. Muscular performance was assessed in terms of Maximum Voluntary Contraction (MVC) and Time to Fatigue at 30\% of MVC on day0 and day30. Recording of muscle performance was done during break hours between 9 am and 12 noon. After explaining the procedure, Hand grip strength of dominant hand was measured using Computerized Hand dynamometer. The participants were advised to sit in a chair with their elbow by their side, flexed to right angles, and a neutral wrist position and subjects were advised to contract the forearm flexor muscles maximally. MVCs were performed with a 2 min rest interval between each contraction. The final MVC was the highest score recorded over five consecutive trials (Jonge et al. 2001).

The subjects were well motivated and received verbal encouragement during the performance of the MVC. After noting the MVC, 30\% MVC was calculated. Subjects were advised to maintain, sustained submaximal contractions of handgrip strength at 30\% intensities, as long as possible voluntarily. Then, time for fatigue for the 30\% MVC was noted. Muscle strength was expressed in Newton and time to fatigue in seconds (Gür, 1997).

\section{Intervention: Pranayama}

The yoga technique was taught and demonstrated by yoga instructor in respective factories. Later subjects were instructed to practice Pranayama (Bhramari and anulomvilom) at home for $20 \mathrm{~min}$ in the morning in empty stomach for 30 days.

Anulom-vilom: The subjects were asked to sit straight comfortably in 'padmasana' and keep the spine straight. The subjects were then asked to close left nostril by their thumb and slowly breathe in with right nostril. Then close the right nostril with ring finger and exhale through the left nostril. They were then asked to keep the right nostril closed, inhale slowly through the left nostril. Then close the left nostril and exhale through the right nostril. This completed one cycle of anulom-vilom (Bamne, 2017). They were asked to repeat 24 such cycles.
Later subjects were asked to breath normally for 2 min and relax. After anulom-vilom, in the same posture of padmasana, Bhramari pranayama was demonstrated and subjects were asked to practice the same at home.

Bhramari pranayama: Subjects were taught to put the thumb of left and right hand over the tragus of respective ears. Eyes closed and the index finger of each hand were placed on the outer corners of the eyelids, the middle finger on the side of the nose near the nostrils, fourth finger above the little finger below the corners of the mouth. Now the subjects were asked to breath from both the nostrils and focus in between the eyelids and imitate the sound of buzzing bee while exhaling through the nasal cavity keeping the mouth closed (Rajkishor et al. 2006). This was repeated for $15 \mathrm{~min}$. There after normal breathing for $2 \mathrm{~min}$ and then to slowly open the eyes.

\section{Statistical Analysis}

SPSS 20.0 was used for statistical analysis. The results were expressed in terms of Mean \pm SD. For comparing the MVC and time for fatigue at 30\% of MVC between pre and post intervention paired $\mathrm{t}$ test was carried out. The level of statistical significance was $\mathrm{p}<0.05$.

\section{RESULTS AND DISCUSSION}

All the subjects were in the age group of 20-40 years with mean age $31.28 \pm 6.53$ years had BMI $21.62 \pm 2.18 \mathrm{~kg} / \mathrm{m}^{2}$. All the subjects had vital parameters within normal range. The recorded values of Maximum Voluntary Contraction (MVC) and Time for Fatigue at 30\% of Maximum Voluntary Contraction before and after pranayama intervention are represented in table 1 .

Table 1: Comparison of MVC (Hand grip strength) and Time to fatigue at $30 \% \mathrm{MVC}$ before and after pranayama intervention

\begin{tabular}{cccccc}
\hline \multirow{2}{*}{ Parameter } & $\begin{array}{c}\text { Pre- } \\
\text { Pranayama }\end{array}$ & \multicolumn{2}{c}{$\begin{array}{c}\text { Post- } \\
\text { Pranayama }\end{array}$} & $\begin{array}{c}\mathbf{p} \\
\text { value }\end{array}$ \\
\cline { 2 - 5 } & Mean & SD & Mean & SD & \\
\hline $\begin{array}{c}\text { MVC - Hand grip } \\
\text { strength (Newton) }\end{array}$ & 153.7 & 20.26 & 159.42 & 18.25 & $0.02^{*}$ \\
$\begin{array}{c}\text { Time to fatigue at 30\% } \\
\text { MVC (Seconds) }\end{array}$ & 189.58 & 25.05 & 210.22 & 18.651 & $0.013^{*}$ \\
\hline
\end{tabular}

MVC - Maximum Voluntary Contraction; $* \mathrm{P}<0.05$ significant, $* * * \mathrm{P}<0.005$ highly significant difference. 
MVC was significantly $(\mathrm{p}<0.02)$ better in Post-Pranayama recording (159.42 \pm 18.25$)$ compared to Pre-Pranayama

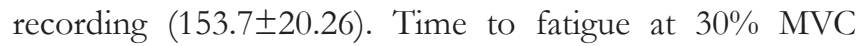
too was significantly higher during Post-Pranayama session (210.22 \pm 18.651$)$ than Pre-Pranayama session (189.58 \pm 25.05$)$.

The workers in garment factories especially women are employed for sewing, ironing and packing etc which are monotonous, continuous and prolonged. Hence, they are exposed to prolonged sitting, prolonged standing, highly repetitive work, lifting of heavy objects, working with their hands lifted to shoulder level or even higher, and with their back bent forward, that have been shown to result in impaired work ability and enhanced long-term sickness (Chandra and Dubey, 2014).

Hence this study aimed to gain fundamental knowledge for the purpose of managing women's occupational health and safety, by finding a simple method for improving the physical performance and overall health which can be easily practiced on daily basis. In this attempt, it was found that muscle performance capability in terms of hand grip strength (strength of upper limb muscles) and time for fatigue were improved significantly on regular practice of pranayama among female garment workers.

The voluntary rhythmic regulation of breathing to calm the mind is called Pranayama (Telles et al. 1994). Pranayama has been demonstrated to produce various physiological benefits (Mohan et al. 2003; Malathi and Parulkar, 1989). The improvement in handgrip strength after regular practice of pranayama can be ascribed to the state of calm alertness, better subjective wellbeing and hypo metabolic state in the subjects which may have resulted in better concentration on the task. This improvement may be due to improved autonomic tone resulting in increased parasympathetic drive, calming of stress responses and neuroendocrine release of hormones (Brown and 2005). Improved autonomic tone may reduce oxygen requirement, and increase the availability of energy which is believed to influence the muscle performance thus hand grip strength (Mohinder and Malik, 1988). Also, cognitive components and non-specific arousal can be the possible factors for the improvement in hand grip strength (Peynirciolu et al. 2000). In a study done by Ray et al., it was evidenced that yogic exercises produce significant increase in muscle endurance and delay in onset of fatigue (Ray et al. 1986). Another study by Raju et al., also found that yoga training resulted in a significant increase in maximal work output with a significantly reduced level of oxygen consumption per unit work (Raju et al. 1994). Regular practice of pranayama increases parasympathetic tone, decreases sympathetic activity, improves cardio-vascular and respiratory functions, decreases the effect of stress and strain on the body and improves physical and mental health (Raju et al. 1994).

Evidence of the effectiveness of regular practice of pranayama for one month duration on physical performance was demonstrated in this study. Hence pranayama may be used as a tool to improve performance of garment workers and reap the benefits of the same in manufacturing and economy. In future, effectiveness of pranayama can be studied in other industries employing unskilled labour in higher proportion.

\section{Acknowledgments}

We thank for the support given by the yoga instructors, garment factory owners and workers who volunteered enthusiastically for the study.

\section{Source of funding - Self \\ Conflict of interest $-\mathrm{Nil}$}

\section{CONCLUSION}

From the present study, it may be concluded that pranayama may bring a positive improvement in the hand grip strength - physical performance.

\section{REFERENCES}

Bamne, S.N. 2017. Immediate effect of anulomvilom pranayama on reaction time of 18- 20 years of age groups. Natural Journal of Physiology, Pharmacoloy, Pharmacy, 7(8): 812-814

Brown, R.P. and Gerbarg, P.L. 2005. Sudarshan Kriya yogic breathing in the treatment of stress, anxiety, and depression: part I-neurophysiologic model. J. Altern. Complement Med., 11(1): 189-201.

Chandra, N. and Dubey, N. 2014. Role of rest period : An ergonomic study on sewing machine operators. Research Journal of Family, Community and Consumer Sciences, 2(7): 12-4.

Gür, H. 1997. Concentric and eccentric isokinetic measurements in knee muscles during the menstrual cycle: a special reference to reciprocal moment ratios. Archives of Physical Medicine and Rehabilitation, 78: 501-505.

Janse de Jonge, X.A.K., Boot, C.R.L., Thom, J.M., Ruell, P.A. and Thompson, M.W. 2001. The influence of menstrual 
cycle phase on skeletal muscle contractile characteristics in humans, J. Physiol., 530(1): 161-166.

Madan Mohan, Jatiya, L., Udupa, R. and Bhavnani, A.B. 2003. Effects of Yoga training on Hand grip, respiratory pressures and pulmonary function. IJJP., 47(4): 387-92.

Malathi, A. and Parulkar, U.G. 1989. Effects of Yogasanas on the visual and auditory reaction time. Indian J. Physiol. Pharmacol., 33: 110-112

Mohinder, P. and Malik, S.L. 1988. Effect of smoking on anthropometric somatotype and grip strength. Indian J Med Res., 87: 494-99.

NITI (Weaving the way for Indian textile industry).

Peynirciolu, Z.F., Thompson, J.L. and Tanielian, T.B. 2000. Improvement strategies in free-throw shooting and gripstrength tasks. J. Gen. Psychol., 127(2): 145-56.
Rajkishor, P., Fumitoshi, M., Bakardjia, H., Vialatte, F. and Cichocki, A. 2006. EEG changes after Bhramari Pranayama Paper Presented at: SCIS \& ISIS.

Raju, P.S., Madhavi, S., Prasad, K.V., Reddy, M.V., Reddy, M.E. and Sahay, B.K. et al. 1994. Comparison of effects of yoga \& physical exercise in athletes. Indian J. Med. Res., 100: 8186.

Ray, U.S., Hegde, K.S. and Selvamurthy, W. 1989. Improvement in muscular efficiency as related to a standard task after yogic exercises in middle aged men. Indian J. Med. Res., 83: 343-48.

Telles, Nagarathna and Nagendra. 1994. Breathing through a particular nostril can alter metabolism and autonomic activities. IJV PP., 38(2): 133-137. 